\title{
Audiological Profile in Children with Autism Spectrum Disorders \\ ${ }^{1}$ Ali Abdel Dayem Ali, ${ }^{2}$ Shoura Youssef Darwish, ${ }^{1}$ Ahmed Mohammed Ahmed Mahmoud, \\ ${ }^{1}$ Mohammed Moneer Mohammed Hassanain \\ ${ }^{1}$ E.N.T Department, Faculty of Medicine, ${ }^{2}$ Neurology Department, Faculty of Medicine, Al-Azhar University Corresponding author: Mohammed M.M. Hassanain, Mobile: 01005027660; Email: audiology_now2003 @yahoo.com
}

\begin{abstract}
Background: Autism spectrum disorder is defined by the Diagnostic Statistical Manual of Mental Disorders $\mathrm{V}$ (DSM V) as a neurobehavioral disorder manifested by persistent deficits in social and communication interaction, deficits in developing, understanding and maintaining relationships, as well as abnormal and fixed interests and repetitive behavior. Symptoms must be present at early childhood and interfere with daily function. The majority of individuals with ASD demonstrate some degree of auditory dysfunction. The level and expression of this dysfunction ranges from deafness and increased thresholds to hyperacusis and difficulty listening with background noise.

Objective: The purpose of this study was to characterize the findings of audiological and electrophysiological hearing assessment in individuals with autism and to compare these findings to those obtained in typically developing individuals. Subjects, Materials \& Method: Forty one Autistic children are divided into two groups:- group (1) Mild to moderate autism were seventeen children \& group (2) Severe autism were twenty four children) were enrolled in this study (Whose ages were 2-6.5 years old) compared with ten typically developing matching peers. All Autistic children in the study had a definite medical diagnosis of Autism according to DSM-5 and based on the severity of symptomatology, ASD children were assessed and divided using CARS score (Childhood autism rating scale). Audiologic evaluation consisted of a case history, otoscopic examinatioin, behavioral free field evaluation, acoustic immittance measures (Tympanogram and Acoustic reflexes), speech audiometry, measurement of distortion product otoacoustic emissions and auditory brain stem response.

Results: Our results support an association between ASD and higher DPOAEs S/N ratios at only $500 \& 750$ Hz. Moreover, ABR in ASD children showed a significant increase in waves III \& V absolute latencies and IIII \& I-V inert peak latencies (In both groups of ASD), with inter aural asymmetry as shortened right ear III-V $\&$ I-V inter peak latencies reflecting a more right ear advantage (mild to moderate group), in addition to a significant decrease in waves V/I amplitude ratio (Both ASD groups).

Conclusion: The OAE responses of children with ASD were highly significantly only at $500 \mathrm{~Hz}$ (Both groups) $750 \mathrm{~Hz}$ (Mild to moderate group). ASD children (either mild to moderate or severe) had a significant increase in ABR waves III \& V peak absolute latencies and I-III \& I-V inter peak latencies. Asymmetrical ABR findings also noted in children with ASD (mild to moderate group) as shortened right ear III-V \& I-V inter peak latencies (more prominent right ear advantage). In ABR also the amplitude of peak I in response to $90 \mathrm{~dB}$ nHL click stimulation was greater than the amplitude of peak V significantly in both groups of ASD children than controls.
\end{abstract}

Keywords: Auditory Brainstem Response - Autism Spectrum Disorders - Acoustic Stapaedial Reflex Otoacoustic emissions - Cytosine, Guanine, Guanine.

\section{INTRODUCTION}

Autism spectrum disorders (ASD) represent a heterogeneous group of specific and non-specific symptoms characterized by pervasive manifestation of partial indicators and cardinal differences in the development of the child with ASD in comparison with the intact individual (1). Autism spectrum disorders (ASD) are highly heritable neurodevelopmental disorders characterized by reduced social interactions, language impairment and repetitive or restricted interests and behaviors ${ }^{(2)}$. Despite strong genetic etiology, diagnosis is based purely on behavioral criteria. However, individuals with ASD display marked phenotypic heterogeneity and frequent medical comorbidities, which have hindered advances in diagnosis and treatment development ${ }^{(3)}$. A recent survey indicated that ASD has an incidence of 1 in 110 (1:70 in males and $1: 315$ in females, although there is significant geographical variability ${ }^{(4)}$.

There is an ample evidence of neuroanatomical dysmorphology in ASD, including differences in neuronal packing density, soma size and number and attenuated dendritic arbors ${ }^{(5)}$. The majority of individuals with ASD demonstrate some degree of auditory dysfunction (6). The level and expression of this dysfunction ranges from deafness and increased thresholds to hyperacusis and difficulty listening with background noise ${ }^{(7)}$.

It is known that children with autism and Asperger syndrome can have perception, attention and memory disorders and often times the presence 
of peripheral and/or central hearing loss is suspected ${ }^{(8)}$.

Therefore, it is necessary to identify alterations in the peripheral and central auditory system in ASD patients, through subjective and objective tests in order to provide an accurate diagnosis and a more effective intervention.

\section{AIM OF THE WORK}

To study the audiological findings in autistic patients and to compare these findings with normal individuals. To correlate the audiological findings in autistic patients with the characteristics of the disease.

\section{SUBJECTS, MATERIALS \& METHOD}

\section{Subjects:-}

A total number of fifty one children (102 ears) were enrolled in the present study. They were divided into three groups according to CARS scores (Childhood Autism Rating Scale) that evaluates 15 aspects of behavior ${ }^{(9)}$. Group (1) included seventeen mild to moderate autistic children (fifteen males and two females with CARS scores ranging between 3036.5), Group (2) included twenty four severe autistic children (seventeen males and seven females with CARS scores 37 and above) while Group (3) included the controls who were ten children (five males and five females with CARS scores below 30). The CARS is a 15-item scale which aids in the identification of children with autism and which distinguishes them from other children with compromised development but without autism. Its importance is based on its ability to differentiate mild-to-moderate from severe autism $^{(\mathbf{1 0})}$. CARS is brief and is appropriate for use with any child over the age of 2 years. It was developed over a 15-year period on the basis of 1,500 autistic children. The scale incorporates diagnostic criteria based on the work of Kanner (1943), Creak (1961), Rutter (1978) and Ritvo \& Freeman (1978) and from the 1980 Diagnostic and Statistical Manual of Mental Disorders (DSM-III) (9). The scale evaluates behavior in 14 domains that are generally affected in autism, plus a single category for general impressions of autism (10). These 15 items are as follows: relating to people, imitation, emotional response, body use, object use, adaptation to change, visual response, listening response, taste, smell, and touch response and use, fear or nervousness, verbal communication, nonverbal communication, activity level, level and consistency of intellectual response and, finally, general impressions. The scores assigned to each domain vary from 1 (within the limits of normality) to 4 (severe autistic symptoms). The total score varies from 15 to 60 and the cutoff point for autism is 30 . Scores between 30 and 36.5 indicates mild to moderate autism while, scores at 37 and above is considered severe autism ${ }^{(9)}$. For both groups (1) \& (2) (mild to moderate and severe autism groups) selection criteria comprised the following: 1Having a definite medical diagnosis of autism (According to DSM-V). 2- An age ranged from 2 to 6.5 years. 3- Absence of neurological diseases. 4Normal middle ear function. While for the control group (Group 3), selection criteria comprised the following: 1- An age ranged from 2 to 6.5 years. 2Normal healthy development. 3- No psychiatric, neurological, speech or hearing problems. 4Normal middle ear functions.

All children were recruited and tested at the audiology unit, Al Hussein University Hospital during the period from October 2014 till May 2016. The study was approved by the Ethics Board of Al-Azhar University.

Equipment: Two-channel Audiometer Interacoustics model AC40 with headphones TDH 39 and bone vibrator B71. Acoustic Immittancemeter Interacoustics model AZ26 with $220 \mathrm{~Hz}$ probe tone. Evoked otoacoustic emissions model Celesta 503 cochlear emission analyzer of Madsen electronics. Auditory brain stem response (ABR) model IHS (Intelligent hearing systems). Sound treated room locally made.

Method:-All children were submitted to: Detailed history taking:- It included personal history, onset, course and duration of complaint, associated medical, prenatal, neonatal and postnatal problems. Special emphasis was done on diseases associated with hearing loss. Moreover, history of consanguineous marriage as well as family history of autism were highlighted, results of previous I.Q tests, EEG \& MRI done before ${ }^{(11)}$. Otological examination: The purpose was to exclude obstruction, infection, congenital malformations and other lesions in the external auditory canal. The TM was examined for perforation, drainage, otitis media and cholesteatoma. Immittancemetry:-This included tympanometry and acoustic reflex threshold measurements (ipsilateral and contralateral reflexes).

For the three groups, speech audiometry was done in the form of speech detection threshold (SDT) or speech reception threshold (SRT).

Auditory brain stem response (ABR):- The children were tested while sleeping either naturally or using sedation in the form of chloral hydrate in a dose of $0.5 \mathrm{cc} / \mathrm{Kg}$. It was done using the IHS evoked potential system in a single-walled sound treated room.

Electrode montage: Two channel recordings consisted of positive recording from Fpz, negative 
from ipsilateral mastoid, and a ground on the forehead. Inter-electrode impedance was minimized using alcohol and rough gauze and was typically no more than 5000 ohms. The electrodes used were silver cup electrodes after applying a conductive paste and attach the electrode firmly with tape.

Procedure and parameters: The stimuli were rarefaction acoustic clicks delivered through headphone at intensity levels of $90 \mathrm{~dB} \mathrm{nHL}$ at a repetition rate of $21.1 \mathrm{p} / \mathrm{s}$. The response was filtered between 300 and $3000 \mathrm{~Hz}$, amplified 100,000 times, recorded over $12 \mathrm{~ms}$ time window, and 1024 sweeps were averaged for each run. Detectability of waves I, III \& V at $90 \mathrm{~dB} \mathrm{nHL}$ as well as their absolute and inter peak latencies were measured until threshold of hearing was obtained (Wave $\mathrm{V}$ threshold). Testing was performed in $20 \mathrm{~dB}$ descending steps. A threshold was defined as the lowest intensity level at which a response could be detected.
Evoked otoacoustic emissions (Distortion product) model Celesta 503 cochlear emission analyzer of Madsen electronics:- The DPOAE tests were performed in a sound treated room using a Madsen pediatric OAE probe assembly (model Celesta 503) fitted to the ear canal. The acoustic stimuli were two continuous pure tones at the socalled primary frequencies of $\mathrm{f} 1$ and $\mathrm{f} 2$. The primary L1 and L2 levels were separately adjusted, and the frequency ratio of $\mathrm{f} 2 / \mathrm{f} 1$ was fixed at 1.22 . The levels of the stimuli were fixed at $\mathrm{L} 1=65$ and $\mathrm{L} 2=55 \mathrm{~dB}$ SPL. The DPOAE measurement was evaluated when the generation of the 2f1-f2 DPOAE occurred by primaries with geometric mean frequencies of $0.5-8 \mathrm{kHz}$. The detection of the DPOAEs was based on the amplitudes being at least $3 \mathrm{~dB}$ above the average level of the noise floor sampled at several frequencies surrounding the emission frequency. The frequency-specific signal/noise ratios (SNRs) in both ears of the children were evaluated.

\section{RESULTS}

Table (1): Results of ipsilateral and contralateral acoustic reflex thresholds at different frequencies between groups:

\begin{tabular}{|c|c|c|c|c|}
\hline $\begin{array}{c}\text { Frequency in } \\
\text { Hertz }\end{array}$ & $\begin{array}{l}\text { Mild to } \\
\text { moderate } \\
\text { G1 }\end{array}$ & $\begin{array}{l}\text { Severe } \\
\text { G2 }\end{array}$ & $\begin{array}{l}\text { Normal } \\
\text { G3 }\end{array}$ & $\mathbf{P}$ \\
\hline Ipsilateral 500 & $93.33 \pm 7.53$ & $95.00 \pm 5.98$ & $98.33 \pm 2.89$ & $\begin{array}{l}\mathbf{P 1}=0.652 \\
\mathbf{P} 2=0.316 \\
\mathbf{P 3}=0.389\end{array}$ \\
\hline Ipsilateral 1000 & $96.25 \pm 3.06$ & $97.19 \pm 4.90$ & $97.50 \pm 5.24$ & $\begin{array}{l}\mathbf{P 1}=0.689 \\
\mathbf{P 2}=0.625 \\
\mathbf{P 3}=0.911\end{array}$ \\
\hline Ipsilateral 2000 & $93.50 \pm 3.35$ & $97.00 \pm 6.75$ & $97.50 \pm 6.12$ & $\begin{array}{l}\mathbf{P 1}=0.300 \\
\mathbf{P 2}=0.226 \\
\mathbf{P 3}=0.884\end{array}$ \\
\hline Ipsilateral 4000 & $90.0 \pm 00$ & $82.50 \pm 3.54$ & $90.00 \pm .00$ & $\begin{array}{c}\mathbf{P 1}=0.333 \\
\mathbf{P 2}=1.0 \\
\mathbf{P 3}=0.095\end{array}$ \\
\hline $\begin{array}{c}\text { Frequency in } \\
\text { Hertz }\end{array}$ & $\begin{array}{l}\text { Mild to } \\
\text { moderate } \\
\text { G1 }\end{array}$ & $\begin{array}{l}\text { Severe } \\
\text { G2 }\end{array}$ & $\begin{array}{l}\text { Normal } \\
\text { G3 }\end{array}$ & $\mathbf{P}$ \\
\hline $\begin{array}{c}\text { Contralateral } \\
500\end{array}$ & $108.33 \pm 2.89$ & $102.00 \pm 5.70$ & $105.00 \pm 00$ & $\begin{array}{l}P 1=0.130 \\
P 2=0.423 \\
P 3=0.656\end{array}$ \\
\hline $\begin{array}{c}\text { Contralateral } \\
1000\end{array}$ & $105.00 \pm 5.00$ & $100.71 \pm 4.50$ & $105.00 \pm 5.00$ & $\begin{array}{c}P 1=0.217 \\
P 2=1.0 \\
P 3=0.217\end{array}$ \\
\hline $\begin{array}{c}\text { Contralateral } \\
2000\end{array}$ & $102.50 \pm 3.54$ & $100.94 \pm 4.21$ & $102.50 \pm 6.45$ & $\begin{array}{c}P 1=0.645 \\
P 2=1.0 \\
P 3=0.620\end{array}$ \\
\hline $\begin{array}{c}\text { Contralateral } \\
4000\end{array}$ & $95.00 \pm 00$ & $91.67 \pm 2.89$ & $93.33 \pm 2.89$ & $\begin{array}{l}P 1=0.423 \\
P 2=0.667 \\
P 3=0.519\end{array}$ \\
\hline
\end{tabular}


Audiological Profile in Children with Autism...

Table (2): Comparison between DPOAE S/N ratio levels at each frequency between groups:

\begin{tabular}{|c|c|c|c|c|}
\hline $\begin{array}{l}\text { Frequency } \\
\text { in Hertz }\end{array}$ & $\begin{array}{c}\text { Mild to } \\
\text { moderate } \\
(\mathrm{N}=17)\end{array}$ & severe $(N=24)$ & Normal $(\mathrm{N}=10)$ & $\mathbf{P}$ \\
\hline 500 & $.06 \pm 7.91$ & $1.65 \pm 6.80$ & $-6.85 \pm 6.61$ & $\begin{array}{l}\mathrm{P} 1=0.488 \\
\mathrm{P} 2=0.019^{*} \\
\mathrm{P} 3=0.003^{*}\end{array}$ \\
\hline 750 & $5.97 \pm 7.07$ & $3.52 \pm 7.34$ & $-.05 \pm 6.13$ & $\begin{array}{c}P 1=0.278 \\
P 2=0.037^{*} \\
\text { P3 }=0.184\end{array}$ \\
\hline 1000 & $6.91 \pm 8.37$ & $4.75 \pm 8.02$ & $2.40 \pm 4.05$ & $\begin{array}{l}P 1=0.372 \\
P 2=0.141 \\
P 3=0.413\end{array}$ \\
\hline 1500 & $13.53 \pm 5.09$ & $11.29 \pm 6.19$ & $12.45 \pm 3.80$ & $\begin{array}{l}P 1=0.201 \\
P 2=0.622 \\
P 3=0.575\end{array}$ \\
\hline 2000 & $13.85 \pm 4.91$ & $13.52 \pm 4.52$ & $11.00 \pm 4.92$ & $\begin{array}{l}P 1=0.712 \\
P 2=0.164 \\
P 3=0.316\end{array}$ \\
\hline 3000 & $21.24 \pm 6.57$ & $19.90 \pm 7.29$ & $19.45 \pm 8.35$ & $\begin{array}{l}P 1=0.564 \\
P 2=0.541 \\
P 3=0.871\end{array}$ \\
\hline 4000 & $19.53 \pm 6.28$ & $20.77 \pm 5.10$ & $20.90 \pm 4.34$ & $\begin{array}{l}\mathbf{P} 1=0.472 \\
\text { P2 }=0.527 \\
\text { P3 }=0.950\end{array}$ \\
\hline 6000 & $10.18 \pm 6.42$ & $12.13 \pm 3.46$ & $13.10 \pm 2.83$ & $\begin{array}{l}P 1=0.186 \\
P 2=0.116 \\
P 3=0.574\end{array}$ \\
\hline 8000 & $9.91 \pm 8.31$ & $12.38 \pm 6.48$ & $11.50 \pm 4.98$ & $\begin{array}{l}P 1=0.267 \\
P 2=0.567 \\
P 3=0.738\end{array}$ \\
\hline
\end{tabular}

Table (3): Mean ABR waves inter peak latencies in ears of groups (1), (2) \& (3):

\begin{tabular}{|c|c|c|c|c|}
\hline Inter peak latencies (G1) & Right & Left & t & P \\
\hline I-III & $2.30 \pm .16$ & $2.30 \pm .17$ & 0.036 & 0.971 \\
\hline III-V & $1.85 \pm 0.17$ & $1.94 \pm 0.18$ & 2.526 & $0.022^{*}$ \\
\hline I-V & $4.14 \pm .23$ & $4.24 \pm .26$ & 3.112 & $0.007^{*}$ \\
\hline $\begin{array}{c}\text { Inter peak latencies } \\
\text { (G2) }\end{array}$ & Right & Left & $\mathbf{t}$ & P \\
\hline I-III & $2.34 \pm .24$ & $2.30 \pm .20$ & 1.328 & 0.197 \\
\hline III-V & $1.86 \pm 0.16$ & $1.89 \pm 0.15$ & 0.583 & 0.566 \\
\hline I-V & $4.21 \pm .22$ & $4.19 \pm .26$ & .367 & 0.717 \\
\hline $\begin{array}{c}\text { Inter peak latencies } \\
\text { (G3) }\end{array}$ & Right & Left & t & P \\
\hline I-III & $2.13 \pm .10$ & $2.07 \pm .16$ & 1.063 & 0.315 \\
\hline III-V & $1.80 \pm 0.14$ & $1.85 \pm 0.18$ & 1.354 & 0.209 \\
\hline I-V & $3.93 \pm .15$ & $3.93 \pm .14$ & 0.098 & 0.924 \\
\hline
\end{tabular}


Table (4): Comparison between ABR waves absolute \& inter-peak latencies between groups:

\begin{tabular}{|c|c|c|c|c|}
\hline $\begin{array}{c}\text { ABR } \\
\text { waves } \\
\text { absolute } \\
\text { latencies } \\
\end{array}$ & $\begin{array}{c}\text { Mild to } \\
\text { moderate (G1) }\end{array}$ & $\begin{array}{l}\text { severe } \\
\text { G2 })(\end{array}$ & $\begin{array}{c}\text { Normal } \\
\text { (G3) }\end{array}$ & $\mathbf{P}$ \\
\hline I & $1.67 \pm .11$ & $1.61 \pm .15$ & $1.64 \pm .12$ & $\begin{array}{l}P 1=0.160 \\
P 2=0.540 \\
P 3=0.583\end{array}$ \\
\hline III & $3.97 \pm .17$ & $3.93 \pm .20$ & $3.74 \pm .14$ & $\begin{array}{c}P 1=0.584 \\
P 2=0.003 * \\
P 3=0.006 *\end{array}$ \\
\hline V & $5.86 \pm .23$ & $5.81 \pm .22$ & $5.57 \pm .15$ & $\begin{array}{l}P 1=0.470 \\
\text { P2 }=0.001 * \\
\text { P3 }=0.004 *\end{array}$ \\
\hline $\begin{array}{c}\text { ABR } \\
\text { waves } \\
\text { inter } \\
\text { peak } \\
\text { latencies }\end{array}$ & $\begin{array}{c}\text { Mild to } \\
\text { moderate (G1) }\end{array}$ & $\begin{array}{l}\text { severe } \\
\text { (G2) }\end{array}$ & $\begin{array}{c}\text { Normal } \\
\text { (G3) }\end{array}$ & $\mathbf{P}$ \\
\hline I - III & $2.30 \pm .15$ & $2.32 \pm .21$ & $2.10 \pm .10$ & $\begin{array}{c}P 1=0.650 \\
P 2=0.007 * \\
P 3=0.002 *\end{array}$ \\
\hline III - V & $1.89 \pm .16$ & $1.87 \pm .13$ & $1.83 \pm .15$ & $\begin{array}{l}P 1=0.681 \\
P 2=0.251 \\
P 3=0.681\end{array}$ \\
\hline I - V & $4.19 \pm .24$ & $4.20 \pm .21$ & $3.93 \pm .11$ & $\begin{array}{c}P 1=0.914 \\
P 2=0.003 * \\
P 3=0.001 *\end{array}$ \\
\hline
\end{tabular}

Table (5): Comparison between ABR waves V/I amplitude ratio levels between groups:

\begin{tabular}{|c|c|c|c|c|}
\hline \multirow{2}{*}{$\mathrm{V} / \mathrm{I}$ ratio } & $\begin{array}{c}\text { Mild to } \\
\text { moderate } \\
(\mathrm{N}=17)(\mathrm{G} 1)\end{array}$ & $\begin{array}{c}\text { severe }(N=24) \\
(G 2)\end{array}$ & $\begin{array}{c}\text { Normal }(\mathrm{N}=10) \\
(\mathrm{G3})\end{array}$ & $\mathbf{P}$ \\
\hline & $1.05 \pm .56$ & $.94 \pm .38$ & $2.25 \pm 2.08$ & $\begin{array}{l}\text { P1 }=0.739 \\
\text { P2 }=0.004 * \\
\text { P3 }=0.001 *\end{array}$ \\
\hline
\end{tabular}

\section{DISCUSSION}

Autism spectrum disorder (ASD) is a neurobehavioral disorder comprised of socialcommunication and social interaction deficits, along with restricted, repetitive behavior (RRB), interests or activities, as is now defined in DSM $5^{\left(\mathbf{( 1 2}^{2}\right)}$. The presence and intensity of these deficits are variable and constitute a heterogenic spectrum ${ }^{(13)}$.

As regard to ipsilateral and contralateral acoustic reflex thresholds at different frequencies, there was no statistical significant differences between right and left ears in each group as well as a none statistical significant differences between groups .This conclusion agree with that of Lukose et al. ${ }^{\text {(14) }}$ who also found that autistic subjects had lower ipsilateral acoustic reflex thresholds at only 500 and $1,000 \mathrm{~Hz}$. However, this finding may be related to deficits in inhibitory neurotransmission. Moreover, there is evidence of disrupted gamma aminobutyric acid (GABA) signaling in the autistic brain ${ }^{(15)}$.

The higher DPOAEs $\mathrm{S} / \mathrm{N}$ ratio levels in the autism groups suggests that outer hair cell activation might be higher in children with autism, particularly at an early age, and this might make them more sensitive to auditory stimuli ${ }^{(\mathbf{1 6})}$.

In the present study, The significantly shorter IPLs in the right side, compared with the left side, found in group (1) was interpreted as an evidence for asymmetry at the lower level of the auditory system and coincide with the well-known cortical asymmetry supporting a right-ear advantage is a possible mechanism for asymmetry ${ }^{(17)}$.

Prolonged ABR waves absolute latencies III $\& \mathrm{~V}$ and inter peak latencies I-III \& I-V, reflect a reduced synaptic efficiency in the auditory pathway in children with Autism, which may provide a 
neurological basis for sensory reaction and linguistic disorder and show a disturbance in the brainstem of the auditory pathway and cortical/subcortical regions in these children ${ }^{(\mathbf{1 8})}$.

The underlying neuropathology that may account for the ABR prolongation in ASD remains unknown. A potential explanation is that prolonged wave $\mathrm{V}$ latencies are due to impaired progression rates of myelination of the auditory system in children with ASD, with some research pointing to marked delays ${ }^{(\mathbf{1 9}) .}$ On the other hand, other researchers suggest that white matter development is accelerated in ASD ${ }^{(20)}$.

Extensive abnormalities in the ASD brainstem have been described, ranging from alterations in size to significant changes to its morphology. Malformations of the superior olivary complex of ASD brainstems have been described in many anatomical studies ${ }^{(\mathbf{2 1})}$.

Disruption of the serotonergic system is also one of the best replicated findings in ASDs. Another possible explanation for prolonged wave $\mathrm{V}$ latency that infants who develop ASD exhibit transient abnormalities during early critical periods of development that normalize at later ages (e.g., early brain overgrowth) ${ }^{(22)}$.

In this study a statistically significant differences existed between groups (1) \& (3) and especially between (2) \& (3) as regard to waves V/I amplitude ratio reflecting marked wave I amplitude relative to wave $\mathrm{V}$ that was more evident in the severe autism group. This finding is in agreement with that observed by Santos et al. (23) who found similar conclusion in their studies on autistic children compared to their controls.

A possible explanation for these findings could be due to abnormal functioning of the descending auditory system associated with the midbrain and/or the presence of other brain abnormalities, likely contribute to the hyperacusis and the abnormal reactions to sounds often observed in ASD children, though the exact underlying neuropathology that accounts for the ABR characteristics observed in ASD children remains unknown ${ }^{(23)}$.

In summary, audiologists play a major role in the early identification and appropriate referral of children with autistic disorder when a disparity between the child' $s$ hearing function and language level is evident, either with or without other social or developmental deficits.

The results of the current study introduced an evidence for the abnormal hearing process in the primary stages of the auditory system in the children with Autism characterized by physiological disorders in the auditory neural pathway. These results offer a promising direction for further research, as they suggest that using infant $\mathrm{ABR}$ recordings may be used not only for clinical assessment of the patient's hearing status but also as a potential marker for early autism diagnosis.

\section{CONCLUSION}

The OAE responses of children with ASD were higher significantly only at $500 \mathrm{~Hz}$ (mild to moderate \& severe groups) \& $750 \mathrm{~Hz}$ (mild to moderate group) than control subjects explained by the overactive outer hair cells. In spite of within normal ABR wave V threshold, ASD children with either mild to moderate or severe degree had a significant increase in ABR waves III \& V peak absolute latencies and I-III \& I-V inter peak latencies in comparison with controls that suggest low brainstem auditory dysfunction. Asymmetrical ABR findings also noted in children with ASD (mild to moderate group) as shortened right ear III-V \& I-V inter peak latencies (more prominent right ear advantage). In ABR also the amplitude of peak I in response to $90 \mathrm{~dB}$ nHL click stimulation was significantly greater than the amplitude of peak V in both groups of ASD children than controls.

\section{REFERENCES}

1- Vitáskovál K , Ríhová A (2012): The current role of speech-language therapists in the diagnosis and complex intervention in children with autism spectrum disorder in the Czech Republic. International Conference on Education and Educational Psychology (ICEEPSY 2012), Procedia, Social and Behavioral Sciences, 69: 1973 1982.

2- Gandal M, Edgar J, Ehrlichman R, Mehta M, Roberts T , Siegel S (2010): Validating Oscillations and Delayed Auditory Responses as Translational Biomarkers of Autism. Biol Psychiatry, 68(12): 1100-1106.

3- Geschwind D (2009): Advances in autism. Annu Review Med., 60: 367-380.

4- IDEA (2008) :Individuals with Disabilities Education Act: Part B Child Count, https://www.ideadata.org/PartBChildCount.asp.

5- Schumann C , Amaral D (2006): Stereological analysis of amygdala neuron number in autism. J. Neurosci., 26(29): 7674-7679.

6- Tomchek S , Dunn W (2007): Sensory processing in children with and without autism: a comparative study using the short sensory profile. American Journal of Occupational Therapy, 61(2): 190-200.

7- Tharpe A, Bess F, Sladen D, Schissel H, Couch S , Schery $T$ (2006): Auditory characteristics of children with autism. Ear Hear, 27(4): 430-441.

8- Matas G, Crivellaro I , Magliaro L (2009): Audiologic and electrophysiologic evaluation in children with psychatric disorders. Braz J Otorhinolaryngology, 75(1): $130-138$

9- Schopler E, Reichler R , Renner B (1988): Childhood Autism Rating Scale (CARS), tenth edition. The Angeles: Western Psychological Services, Los Angeles, CA.

10-Magyar C , Pandolfi V (2007): Factor structure evaluation of the childhood autism rating scale. J Autism Dev Disord., 37: 1787-1794 
11-American Academy of Pediatrics (2007): Principles and guidelines for early hearing detection and intervention programs. Joint Committee on Infant Hearing Pediatrics, 120(4): 898-921.

12-American Psychiatric Association (2013): Diagnostic and statistical manual of mental disorders, fifth edition. Washington, DC: American Psychiatric Publishing.

13-Johnson C , Myers S (2007): Identification and evaluation of children with autism spectrum disorders. Pediatrics, 120: 1183-1215.

14-Lukose R, Brown K, Barber C , Kulesza R (2013): Quantification of the Stapedial Reflex Reveals Delayed Responses in Autism. Autism Res., 6(5): 344-353.

15-Oblak A, Gibbs T , Blatt G. (2011): Reduced GABAA receptors and benzodiazepine binding sites in the posterior cingulate cortex and fusiform gyrus in autism. Brain Research, 1380: 218-228.

16-Taş M, Yılmaz Ş, Bulut E, Polat Z, Taş A (2017): Otoacoustic Emissions in Young Children with Autism. J Int Adv Otol., 13(3): 327-332.

17-Sininger Y , Cone-Wesson B (2006): Lateral asymmetry in the ABR of neonates: evidence and mechanisms. Hear Res., 212: 203-211.
18-Magliaro F, Scheuer C, Assumpção Júnior F , Matas C (2010): Study of auditory evoked potentials in autism. Pro-Fono Scientific Update Magazine, 22(1): 31-6.

19-Perkins T, Stokes M, McGillivray J , Bittar R (2010): Mirror neuron dysfunction in autism spectrum disorders. $\mathbf{J}$ Clin Neurosci., 17(10): 1239-1243.

20- Weinstein M, Ben-Sira L, Levy Y, Zachor D, Ben Itzhak E, Artzi M, Tarrasch R, Eksteine P, Hendler T, Ben Bashat D (2011): Abnormal white matter integrity in young children with autism. Human Brain Mapping, 32: 534-543.

21-Randy J, Lukose R, Stevens L (2011): Malformation of the human superior olive in autistic spectrum disorders. Brain Research, 1367: 360-371.

22-Amaral D, Schumann C , Nordahl C (2008): Neuroanatomy of autism. Trends in Neurosciences, 31: 137-145.

23-Santos M, Marques C, Nóbrega Pinto A, Fernandes R, Coutinho M, Almeida E , Sousa C (2017): Autism Spectrum Disorders and the Amplitude of Auditory Brainstem Response Wave I. Autism Res., 10(7): 13001305 . 